\title{
GRAU DE HIDROMETRIA DO CÓRTEX DE SEIS ESPÉCIES ARBÓREAS DA CAATINGA
}

\author{
Marilena Ferrari (1) \\ Laise de H. C. Andrade (1) \\ Maria Cleoneide S. Brito (1) \\ Silas C. Brito Jr. (1)
}

\begin{abstract}
RESUMO - O grau de hidrometria do córtex é um dos principais fatores que influenciam o estabelecimento de epífitas no tronco das árvores. Considerando a ausência de informações sobre o assunto na literatura para as espécies da caatinga, o grau de absorção de água pelo córtex de seis espécies típicas de região semi-árida (Salgueiro-PE) foi determinado. Oito amostras de $100 \mathrm{~cm}^{2}$, com três repetições de cada espécie, foram coletadas em árvores adultas e sadias; as amostras foram colocadas em estufa $\left(100^{\circ} \mathrm{C}\right)$ por três dias, para obtenção do peso seco, mantidas em seguida em atmosfera saturada (UR 90-100\%) por quatro dias, pesadas, imersas em água por dois dias e pesadas, para determinar a capacidade de absorção de água. $\mathrm{Pa}$ ra cada espécie, correspondendo ao peso $\left(\mathrm{g} / 100 \mathrm{~cm}^{2}\right)$ de (1) córtex desidratado, (2) água absorvida em atmosfera saturada e (3) água absorvida após imersão, os seguintes valores foram obtidos: Schinopsis brasiliensis Engl. (braúna): (1) 43,15; (2) 7.75; (3) 27,77; Spondias tuberosa Arr. Cam. (umbuzeiro): (1) 17,98; (2) 3,50; (3) 20,97; Bumelia sartorum Mart. (quixabeira): (1) 30,80; (2) 7,17; (3) 46,40; Mimosa hostilis Benth. (jurema-preta): (1) 35,77; (2) 7.63; (3) 29,34; Aspidosperma pyrifolium Mart. (pereiro): (1) 16,36; (2) 2.64; (3) 12,72; Croton sonderianus Muell. Arg. (marmeleiro): (1) 13,73 ; (2) 2,22 ; (3) 13,53 . Considerando a água absorvida pelo córtex após imersão. as forófitas foram classificadas como: muito xéricas (pereiro e marmeleiro), xéricas (umbuzeiro, braúna, jurema-preta) e pouco xéricas (quixabeira).
\end{abstract}

Palavras-chave: epífitas; caatinga; córtex; hidrometria.

\section{ABSTRACT - HIDROMETRIC RATE OF THE CORTEX OF SIX ARBOREOUS SPECIES IN THE CAATINGA.}

The hidrometric rate of the bark is one of the main elements that influences the settlement of epiphytes on the trunk of trees. Considering there's no information in literature on this subject, for the species in the "caatinga", the extent of absorption

(1) Departamento de Botânica, Centro de Ciências Biológicas, Cidade Universitária, Recife-PE-Brasil. 
of water by the cortex of six species typical of the semi dry region (Salgueiro-PE) was determined. Eight samples of $100 \mathrm{~cm}^{2}$, with three repetitions of each species, were collected in healthy adult trees. The samples were placed in a stove $\left(100^{\circ} \mathrm{C}\right)$ for three days, to obtain dry weight. They were kept in saturated atmosphere (UR $90-100 \%$ ) for four days, weighed, immersed in water (2 days) and weighed again to determine the capacity of the water absorption. For each species, corresponding to weight $\left(\mathrm{g} / 100 \mathrm{~cm}^{2}\right)$ of (1) dehydrated bark, (2) water absorbed in saturated atmosphere and (3) water absorbed after immersion, these values were obtained: Schinopsis brasiliensis Engl. (braúna): (1) 43,15; (2) 7,75; (3) 27,77; Spondias tuberosa Arr. Cam. (umbuzeiro): (1) 17,98; (2) 3,50; (3) 20,97; Bumelia sartorum Mart. (quixabeira): (1) 30,80; (2) 7,17; (3) 46,40; Mimosa hostilis Benth. (jurema-preta): (1) 35.77; (2) 7.63; (3) 29,34; Aspidosperma pyrifolium Mart. (pereiro): (1) 16,36 ; (2) 2,64 ; (3) 12,72 ; Croton sonderianus muell. Arg. (marmeleiro): (1) 13,73 ; (2) 2,22; (3) 13,53. Considering the water absorbed by the cortex after immersion, the phorophytes were classified as: very xeric ("pereiro", "marmeleiro"), xeric ("umbuzeiro", "braúna", "jurema-preta") and low xeric ("quixabeira").

KEY WORDS: epiphytes; bark; "caatinga"; hidrometric rate.

\section{Introduçāo}

A região das caatingas ocupa uma área considerável da região nordestina. Embora nela ocorra uma das formações vegetais mais importantes do país, dispõe-se ainda de poucas informações sobre as espécies que nela vivem, especialmente sob o ponto de vista ecológico. Quase nada se sabe, por exemplo, sobre as espécies de hábito epífita ocorrentes nos diferentes tipos de caatinga, sejam vegetais superiores, como bromeliáceas e orquidáceas, sejam inferiores, como briófitas e líquens.

No estudo ecológico das epífitas, um dos aspectos importantes na sua relação com a forófita é a determinação do grau de hidrometria do córtex da planta que serve de suporte, ou seja, o teor máximo de água que este córtex pode absorver (Le Blanc, 1962).

Para as plantas das caatingas, apenas Lima (1982) informa com detalhes características morfológicas e organolépticas do córtex, visando a identificação de trinta espécies arbóreas, entre as quais se incluem Bumelia sartorum Mart., Mimosa hostilis Benth., Schinopsis brasiliensis Engl., Spondias tuberosa Arr. Cam., Croton sonderianus Muell. Arg. e Aspidosperma pyrifolium Mart. No referido trabalho, encontra-se referência à presença de epífitas apenas na descrição da jurema vermelha (Mimosa sp.), não sendo abordado o grau de hidrometria do córtex das espécies estudadas.

Em outros países, tais informações de há muito são disponíveis (Schwankl, 1956; Barkman, 1958; Le Blanc, 1962), porém no Brasil temos apenas trabalhos recentes, como o de Ranal (1988), que estabeleceu, entre outros fatores, o teor de umidade do substrato, visando melhor entendimento quanto à 
ocorrência de esporófito de pteridófitas epífitas e o de Ferrari et al. (1989), que estudaram o grau de hidrometria do córtex de Pterocarpus violaceus Vog., espécie comum na zona da mata de Pernambuco, relacionando as epífitas nele presentes.

Considerando a inexistência de informações sobre o grau de hidrometria das plantas da caatinga visou-se, no presente trabalho, determinar o teor de água que é capaz de absorver o córtex de seis espécies arbóreas, típicas deste tipo de vegetação, relacionando-o com as epífitas nelas presentes. Foram selecionadas, devido à freqüência com que são encontradas na zona das caatingas de Pernambuco e sua importância como produtoras de madeiras e frutos comestíveis (Andrade-Lima, 1960, 1970), seis das trinta espécies estudadas por Lima (1982), representando as famílias Leguminosae (Mimosa hostilis Benth.), Euphorbiaceae (Croton sonderianus Muell. Arg.), Anacardiaceae (Schinopsis brasiliensis Engl. e Spondias tuberosa Arr. Cam.), Apocynaceae (Aspidosperma pyrifolium Mart.) e Sapotaceae (Bumelia sartorum Mart.).

\section{Material e Métodos}

Objetivando-se determinar o grau de hidrometria do córtex do tronco das seis espécies selecionadas, foram estudados dezoito exemplares de porte arbóreo, ocorrentes em Salgueiro, no sertão central de Pernambuco. Adotou-se, em linhas gerais, a metodologia de Le Blanc (1962), com as modificações introduzidas por Ferrari et al. (1989)

De cada espécie a ser estudada, foram selecionados três indivíduos adultos e sadios, tendo sido coletadas oito amostras de $100 \mathrm{~cm}^{2}$ de córtex por indivíduo. (Fig. 1).

Na câmara úmida utilizada, do tipo "walk in", as amostras, em número de 24 por espécie, foram arrumadas sobre cartões plastificados, procurando-se manter a superfície externa do córtex voltada para cima. As amostras ali permaneceram por um período de 4 dias, numa atmosfera saturada de vapor d'água por meio de um vaporizador automático, que manteve a umidade do ambiente entre $90-100 \%$ (Fig. 1).

Para se obter a quantidade máxima de água absorvida pelo córtex, cada amostra de $100 \mathrm{~cm}^{2}$ foi imersa em água, utilizando-se cubas de papel alumínio $(15,0 \times 12,0 \times 3,5 \mathrm{~cm})$, hermeticamente fechadas, nas quais mantiveram-se por 2 dias (Fig. 1).

Para cada indivíduo estudado, foi determinada a média do peso seco do córtex $\left(\mathrm{g} / 100 \mathrm{~cm}^{2}\right)$ e calculado seu respectivo desvio padrão, procedendo-se da mesma maneira com os valores referentes à quantidade de água absorvida, por imersão ou da atmosfera saturada $\left(\mathrm{g} / 100 \mathrm{~cm}^{2}\right)$. Foram realizadas análises de correlação entre os valores referentes ao peso seco do córtex e à água por ele absorvida em atmosfera saturada.

Estimou-se a altura das árvores, mediu-se a circunferência do tronco à altura de $1,20 \mathrm{~m}$ e documentou-se o aspecto do córtex de cada espécie, bem como a ocorrência de epífitas nele presentes, sendo tomadas fotografias no campo, 
dos diferentes exemplares examinados.

Os dados diários de precipitação pluviométrica, umidade relativa do ar (9-15-21h) e temperatura, referentes ao mês de outubro de 1988, tomados no posto de Cabrobó-PE, distante cerca de $50 \mathrm{Km}$ de Salgueiro, foram fornecidos pelo 3ㅇ Distrito do Instituto Nacional de Meteorologia, sediado em Recife.

Foram coletadas amostras dos exemplares que se encontravam em floração/frutificação para identificação das espécies. $O$ marmeleiro que não se encontrava em floração e frutificação e a brauna, que se encontrava em fase de frutificação, foram identificados pelo fruto e/ou casca (LIMA, 1982) retornando-se ao local na época de floração para coleta de amostras e confirmação da espécie em estudo. Exsicatas representativas do material estudado encontram-se depositadas no herbário UFP sob números 7791, 7792, 7793, 7794, 7796 e 7797.

\section{Resultados}

\section{Descrição dos indivíduos estudados}

Os indivíduos estudados no presente trabalho apresentaram as seguintes caraterísticas quanto à estimativa de altura, diâmetro do tronco a $1,20 \mathrm{~m}$, ocorrência de epífitas, caducifolia e aspectos do córtex como rugosidade, espessura, coloração e esfoliação:

Bumelia sartorum Mart., da família Sapotaceae, conhecida vulgarmente com quixabeira, apresenta córtex de coloração escura, superfície áspera e rugosa, com sulcos longitudinais muito longos e profundos (Fig. 2). O diâmetro do tronco, bem como a altura das árvores examinadas apresentam valores médios de $0,40 \mathrm{~m}$ e $7,29 \mathrm{~m}$, respectivamente. Os indivíduos estudados encontravam-se com a copa coberta de folhas, notando-se em dois deles a presença de flores. Quanto à ocorrência de epífitas, foram observados poucos líquens em dois dos indivíduos e bromeliáceas do gênero Tillandsia em apenas um deles.

Mimosa hostilis Benth., da família Leguminosae, subfamília Mimosoidae, conhecida vulgarmente como jurema-preta, possui córtex de coloração escura, apresentando superfície rugosa, com blocos irregulares e muito espessos (Fig. 3). Os valores médios referentes ao diâmetro do tronco e à altura das árvores examinadas foram de $0,24 \mathrm{~m}$ e $5,13 \mathrm{~m}$, respectivamente. Todos os três indivíduos apresentavam-se desprovidos de folhas na ocasião da coleta das amostras. Raras epífitas, representadas por líquens, estavam presentes nos troncos de dois dos indivíduos estudados.

Schinopsis brasiliensis Engl., pertencente à família Anacardiaceae e conhecida sob o nome vulgar de braúna, apresenta córtex de superfície rugosa, coloração escura, quase negra, com sulcos longitudinais e fendas transversais, que delimitam blocos retangulares muito espessos (Fig. 4). O diâmetro do tron- 
co como também a altura das árvores examinadas apresentam em média $0,50 \mathrm{~m}$ e $8,16 \mathrm{~m}$, respectivamente. Todos os três indivíduos estudados encontravam-se com folhas na ocasião da coleta de amostras. No que diz respeito à presença de epífitas, só um dos indivíduos apresentou líquens em seu tronco, mesmo assim em pequena quantidade.

Spondias tuberosa Arr. Cam., pertencente à família Anacardiaceae e conhecida sob o nome vulgar de umbuzeiro, apresenta córtex de coloração pouco escura, de superfície rugosa e esfoliante, com placas aproximadamente arredondadas, de espessuras variáveis (Fig. 5). Para o diâmetro do tronco e também para a altura das árvores, foram encontrados valores médios correspondentes a $0,35 \mathrm{~m}$ e $5,13 \mathrm{~m}$, respectivamente. Os três exemplares estudados encontravam-se desprovidos de folhas, na ocasião do estudo, registrando-se em todos a presença de bromeliáceas do gênero Tillandsia, enquanto líquens foram observados em apenas dois deles.

Croton sonderianus Muell. Arg., da família Euphorbiaceae, vulgarmente conhecida como marmeleiro, apresenta córtex de espessura delgada, coloração mais clara em relação à das demais espécies e superfície áspera e esfoliante (Fig. 6). O diâmetro do tronco e a altura das árvores apresentam valores médios de $0,10 \mathrm{~m}$ e $4,59 \mathrm{~m}$. As árvores não possuíam folhas por ocasião da coleta das amostras. A ocorrência de líquens foi evidenciada nos três indivíduos estudados e a de bromeliáceas do gênero Tillandsia apenas em dois exemplares.

Aspidosperma pyrifolium Mart., da família Apocynaceae, conhecida vulgarmente como pereiro, possui córtex áspero, de espessura média, coloração clara, com fendas longitudinais e transversais pouco profundas (Fig. 7). O diâmetro do tronco e a altura das árvores apresentam valores médios de $0,29 \mathrm{~m} \mathrm{e}$ $6,75 \mathrm{~m}$. Os exemplares estudados encontravam-se em fase de frutificação, estando desprovidos de folhas. Dentre as epífitas, foram observados líquens nos três indivíduos estudados, dois dos quais serviam de suporte também para bromeliáceas do gênero Tillandsia, encontrando-se, ainda, macrofungos em um deles.

Nos dezoito indivíduos, observou-se que os raios solares incidiam diretamente sobre o tronco e os ramos das árvores caducifólias e só indiretamente sobre as mesmas partes das árvores que se apresentavam com folhas.

\section{Peso do córtex}

O peso do córtex desidratado não variou significativamente entre indivíduos de uma mesma espécie. diferindo entretanto quando se considera o conjunto das seis espécies estudadas (Tabela 1).

A Fig. 8 representa os valores referentes aos pesos do córtex de cada espécie, correspondentes à média dos três indivíduos examinados; observa-se que, mesmo apresentando pesos médios distintos, a diferença não é significati- 
va entre $S$. brasiliencis e $M$. hostilis. bem como entre esta e $B$. sartorum ou $S$. tuberosa embora as duas últimas espécies difiram entre si. Evidenciam-se nesta figura dois grupos de espécies com relação ao peso do córtex, ficando no primeiro $B$. sartorum. $M$. hostilis e $S$. brasiliensis e no segundo $S$. tuberosa. $C$. sonderianus e A. pyrifolium.

\section{Grau de Hidrometria}

A capacidade máxima de absorção de agua por imersão foi observada em B. sartorum $\left(46.40 \mathrm{~g} / 100 \mathrm{~cm}^{2}\right)$ e as mínimas em $A$. pyrifolium $(12.72$ $\mathrm{g} / 100 \mathrm{~cm}^{2}$ ). quantidades estas proporcionais ao peso do córtex desidratado (Fig. 8). $M$. hostilis. $S$. brasiliensis e $S$. tuberosa absorveram. em média. 29.34 $\mathrm{g} / 100 \mathrm{~cm}^{2} .27 .77 \mathrm{~g} / 100 \mathrm{~cm}^{2}$ e $20,97 \mathrm{~g} / 100 \mathrm{~cm}^{2}$. não se verificando proporção entre os valores referentes ao peso do córtex e a quantidade máxima de água por ele absorvida.

Em atmosfera saturada. as amostras do córtex de três das seis espécies estudadas. absorveram entre $2.2-3.5 \mathrm{~g} / 100 \mathrm{~cm}^{2}$ (C. sonderianus, A. pyrifolium e $S$. tuberosa). ficando $B$. sartorum. $M$. hostilis e $S$. brasiliensis na faixa de 7.1-7.7 g/100 $\mathrm{cm}^{2}$ (Fig. 8).

Foi constatada uma correlação linear entre o peso do córtex desidratado e o teor de água que ele é capaz de absorver quando exposto a uma atmosfera saturada. em cinco das seis espécies ora em estudo (Figs. 9-14); esta correlação é bem evidente quando se consideram os valores relativos a $A$. pyrifolium $\left(\mathrm{r}^{2}=\right.$ $0.96)$. $M$. hostilis $\left(\mathrm{r}^{2}=0.92\right)$ e $C$. sonderianus $\left(\mathrm{r}^{2}=0.72\right)$, não existindo apenas para $S$. tuberosa $\left(\mathrm{r}^{2}=0.33\right)$.

De acordo com a quantidade de água absorvida pelo córtex. as espécies estudadas podem ser classificadas. quanto a seu grau de hidrometria, como muito xéricas (C. sonderianus e A. pyrifolium) ou pouco xéricas ( $M$. hostilis e $S$. brasiliensis). como mostra a Tabela $2 ; S$. tuberosa fica numa posição intermediária (xérica) quando se considera o valor da quantidade máxima de água absorvida. classificando-se como muito xérica quando se considera a quantidade de água absorvida da atmosfera saturada; da mesma forma. $B$. sartorum pode ser enquadrada como a menos xérica das seis espécies de acordo com a quantidade máxima de água absorvida ou pode cair para uma posição mais próxima à de $M$. hostilis e $S$. brasiliensis, quando se considera o teor de água encontrado após exposição à atmosfera saturada.

\section{Dados climatológicos}

Em Cabrobó. no mês em que foram tomadas as amostras (outubro), registrou-se apenas $126 \mathrm{~mm}$ de chuva. concentrados em dois dias. coincidindo ambos com a ocasião em que as mesmas foram coletadas.

A temperatura média do mês ficou em $27,8^{\circ} \mathrm{C}$, com máxima absoluta de $36,1^{\circ} \mathrm{C}$ e mínima de $19.2^{\circ} \mathrm{C}$.

A umidade relativa do ar, em média $49 \%$, variou entre $23 \%$ (15h) e $90 \%$ 
(9h). no mesmo mês.

\section{Discussōes e Conclusōes}

As seis espécies estudadas no presente trabalho. freqüentes em regiões semi-áridas. possuem córtex com capacidade de absorver água da atmosfera igual ou mesmo um pouco superior à encontrada em algumas plantas que vivem em regiōes de clima mais úmido, como as da zona da mata de Pernambuco.

Ferrari et al. (1989), por exemplo, citam teores entre $3.0-5.0 \mathrm{~g} / 100 \mathrm{~cm}^{2}$ de água. absorvidos pelo córtex de Pterocarpus violaceus Vog.. numa área de mata do município do Recife, teores estes próximos aos encontrados para $A$. pyrifolium, C. sonderianus e $S$. tuberosa. situados na faixa de $2,0-3,5 \mathrm{~g} / 100 \mathrm{~cm}^{2}$ ou de $B$. sartorum. $M$. hostilis e $S$. brasiliensis, que absorvem cerca de 7.5 $\mathrm{g} / 100 \mathrm{~cm}^{2}$. Chega-se à mesma evidência quando se considera a capacidade máxima de absorção de água pelo córtex das plantas da caatinga e da espécie da mata úmida. ou seja. uma faixa de $10,0-23.0 \mathrm{~g} / 100 \mathrm{~cm}^{2}$ para $P$. violaceus e $12.0-27,0 \mathrm{~g} / 100 \mathrm{~cm}^{2}$ para quatro das seis espécies, absorvendo $M$. hostilis e $B$. sartorum entre $29.0-46.0 \mathrm{~g} / 100 \mathrm{~cm}^{2}$ de água.

A classificação das plantas como forófitas através do grau de hidrometria do córtex. tem sido feita com base na quantidade máxima de água absorvida por superfície do tronco $\left(100 \mathrm{~cm}^{2}\right)$, encontrada após um determinado período de imersão (Le Blanc, 1962). De acordo com este critério. B. Sartorum seria a forófita que ofereceria habitat menos xérico dentre as espécies estudadas. enquanto $A$. pyrifolium e $C$. sonderianus seriam as mais xéricas.

Nas regiões temperadas. as forófitas consideradas mais xéricas, como $\mathrm{Fa}$ gus grandifolia, Betula populifolia e Tsuga canadensis são capazes de absorver entre 21.0-29.0g de água para cada $100 \mathrm{~cm}^{2}$ de córtex (Le Blanc, 1962), valores equivalentes aos encontrados para $S$. tuberosa. $S$. brasiliensis e $M$. hostilis; por esta mesma classificação, $B$. sartorum seria enquadrada como mésica. com grau de hidrometria semelhante ao de Tilia americana, citada por Le Blanc (1962).

Todavia, quando exemplares pertencentes às seis espécies estudadas, foram observados no campo, em Salgueiro. no sertão de Pernambuco, constatouse que a ocorrência e diversidade de epífitas em A. pyrifolium e C. sonderianus, enquadradas como forófitas muito xéricas pelos dois critérios. era igual ou mesmo superior ao das quatro outras espécies estudadas. Da mesma forma. apesar da semelhança no grau de hidrometria verificada entre $P$. violaceus ocorrente na mata e os das plantas da caatinga ora estudadas, estas últimas não apresentam uma quantidade de epífitas equivalente àquela, cujos indivíduos servem de suporte para diversos grupos de vegetais, desde líquens. briófitas e pteridófitas até angiospermas. como aráceas, orquidáceas e bromeliáceas (Ferrari et al., 1989).

No estudo da vegetação epifítica, deve-se levar em consideração, além do grau de hidrometria. outros aspectos, da forófita, tais como a rugosidade do córtex, a inclinação do tronco, a arquitetura da árvore. a caducifolia, a densidade dos indivíduos, fatores estes que influenciam na instalação e sobrevivência 
das epífitas. além dos ambientais como, por exemplo, a precipitação pluviométrica, temperatura e umidade relativa do ar.

As seis espécies estudadas têm, potencialmente, capacidade de abrigar epífitas, pelo grau de hidrometria apresentado pelo córtex; a ausência ou a baixa frequência das mesmas deve ser atribuída à interferência das condições climáticas adversas verificadas na caatinga. Em 1988, por exemplo, no mês em que foram realizadas as coletas, toda a chuva que caiu em Cabrobó, próximo ao local de estudo. concentrou-se em apenas dois dias; a umidade relativa do ar manteve-se baixa, estando este município localizado às margens do rio São Francisco, registrando-se, em média, $49 \%$, embora chegasse aos $90 \%$ em certas horas do dia.

De fato, na subzona do sertão de Pernambuco predomina um clima tropical quente, com secas acentuadas no inverno; o período chuvoso concentra-se em apenas três meses, comumente entre fevereiro e abril, com regime pluviométrico apresentando grande variação espacial e temporal (Reis, 1976). Em Parnamirim. por exemplo, localizado a poucos quilômetros de Salgueiro, registrou-se em 65 anos uma pluviosidade média anual de apenas $560 \mathrm{~mm}$. sempre concentrada num pequeno período do ano (Silva. 1985). A umidade relativa do ar é também muito baixa nessa região, sendo inferior a $70 \%$ durante a maior parte do ano (Lima. 1982; Silva, 1985).

Embora o clima obviamente interfira na quantidade de água presente no córtex das árvores, Ferrari et al. (1989) encontraram valores muito semelhantes para o teor hídrico apresentado pelo córtex de $P$. violaceus, em amostras tomadas durante a estação seca $\left(1.7-4.0 \mathrm{~g} / 100 \mathrm{~cm}^{2}\right)$ e a chuvosa $\left(2,0-4,0 \mathrm{~g} / 100 \mathrm{~cm}^{2}\right)$; as citadas autoras concluíram que o córtex da espécie em questão retêm uma quantidade de água correspondente a cerca de $50 \%$ daquela que é capaz de absorver após exposto por 4 dias à uma atmosfera saturada; o equilíbrio encontrado no campo seria, portanto, mantido mediante uma boa capacidade de retenção de água. associada a uma eficiente absorção da água presente no ar circundante, considerando-se os elevados índices de umidade registrados na zona da mata de Pernambuco durante a maior parte do ano.

É possível que o córtex de $A$. pyrifolium e de $C$. sonderianus possuam maior capacidade de retenção de água absorvida, permanecendo com um teor mais favorável à sobrevivência das epífitas por um período mais prolongado que $B$. sartorum ou $S$. brasiliensis, por exemplo; estas, não possuindo a mesma capacidade, perderiam rapidamente a água absorvida. ofertando na prática um substrato mais para xérico do que para mésico, às epífitas instaladas em seus troncos mesmo permanecendo com folhas na estação seca.

Levando-se em conta as considerações apresentadas acima, uma classificação mais correta das forófitas conforme o grau de hidrometria devesse talvez basear-se numa relação entre o teor de água que o córtex é capaz de absorver da atmosfera e daquele que é capaz de reter; se fosse assim calculado o grau de hidrometria de $A$. pyrifolium e $C$. sonderianus, é possível que fosse encontrado um outro posicionamento para as mesmas, classificando-as como menos xéricas que as demais. 
Estudos futuros, que determinem o grau de hidrometria, através do coeficiente proposto, assim como a sua variação para diferentes estações do ano, associados ao estabelecimento do índice de epifitismo, realizados com diferentes espécies e ecossistemas, poderão confirmar esta proposição.

\section{Agradecimentos}

Os autores agradecem ao Prof. Antônio Lisboa, da Universidade Federal de Pernambuco, a ajuda na análise estatística dos dados.

\section{Referências Bibliográficas}

ANDRADE-LIMA, D. de. 1960. Estudos fitogeográficos de Pernambuco. Arquivos do Instituto de Pesquisas Agronômicas, Recife, 5: 305-341.

—. 1970. Recursos vegetais de Pernambuco. Boletim Técnico do Instituto de Pesquisas Agronômicas. Recife, 41: 1-32.

BARKMAN, J. J. 1958. Phytosociology and ecology of Criptogamic epiphytes. Van Gorcum and Co., Assen, 628 p.

FERRARI, M.; ANDRADE, L. de H. C. \& DUARTE, M. T. M. B. 1989. Grau de hidrometria do córtex e epitifismo em três indivíduos de Pterocarpus violaceus Vog. existentes no Jardim Botânico do Curado (Recife-PE). Revista nordestina de biologia (suplemento): entregue para publicação.

LE BLANC, F. 1962. Hydrométrie des écorces et épiphytisme. Revue Canadienne de Biologie, 21(1): 41-45.

LIMA, J. L. S. de. 1982. Reconhecimento de trinta espécies arbóreas e arbustivas da caatinga através da morfologia da casca. Dissertação de Mestrado. Universidade Federal Rural de Pernambuco, Recife.

RANAL, M. A. 1988. Estabelecimento e desenvolvimento da geração esporofítica de Pteridófitas em mata seca semidecídua do Estado de São Paulo. Tese de Doutorado. Universidade Estadual Paulista "Júlio de Mesquita Filho". Rio Claro.

REIS, A. C. de S. 1976. Clima de Caatinga. Anais da Academia Brasileira de Ciências, 48(2): 325-335.

SCHWANKL, A. 1956. Bark. Thames and Hudson, London. 100 p.

SILVA. G. C. da. 1985. Flora e vegetação das depressões inundáveis da região de Ouricuri-PE. Dissertação de Mestrado. Universidade Federal Rural de Pernambuco, Recife. 


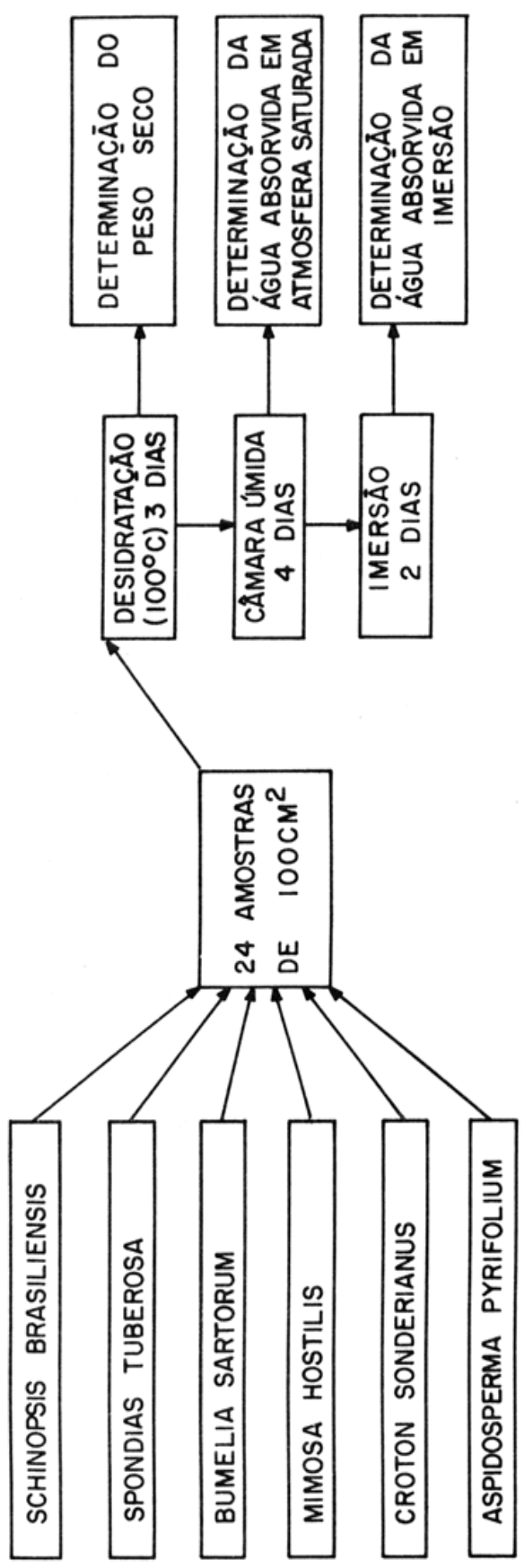

옴

כ

햄

오 인

เి

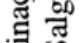

可

을

ฐ

퐁 푬

当

. ํㅗㄹ

응 $\frac{\text { s }}{0}$

ऽै

त $\frac{4}{2}$

불 우

总氮

范 


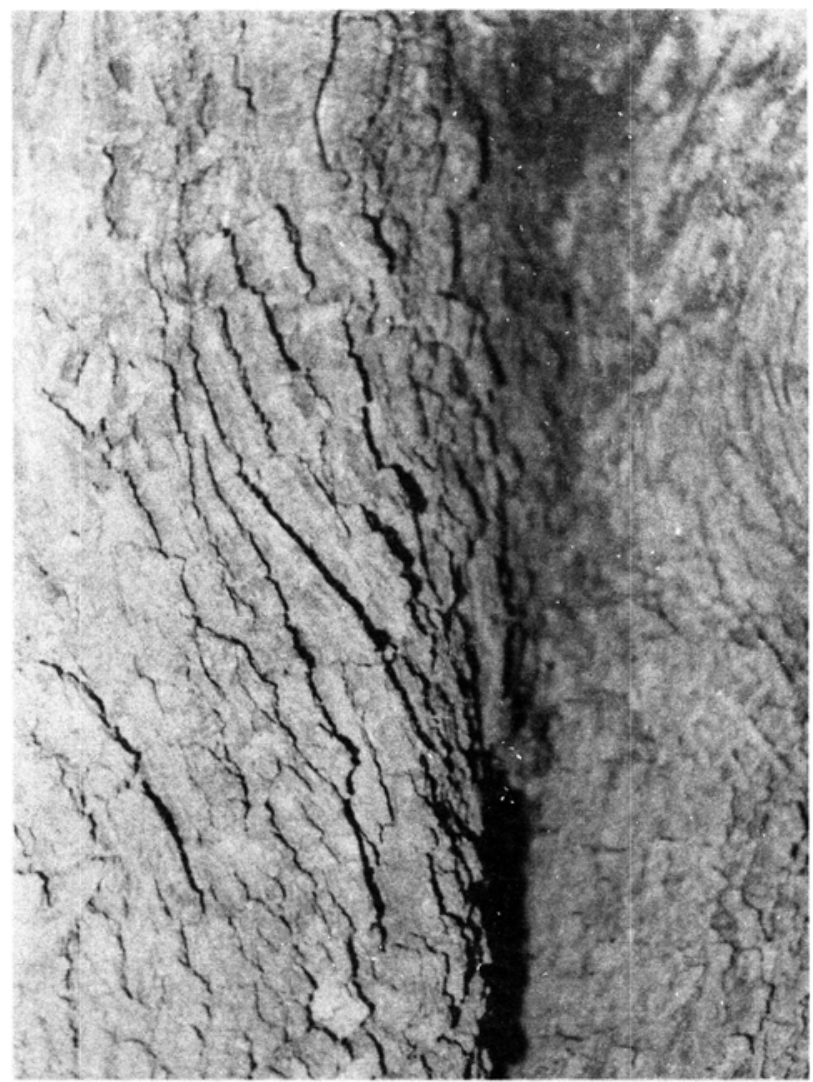

Figura 2 - Aspecto do córtex de Bumelia sartorum Mart., (quixabeira) ocorrente em Salgueiro-PE. 


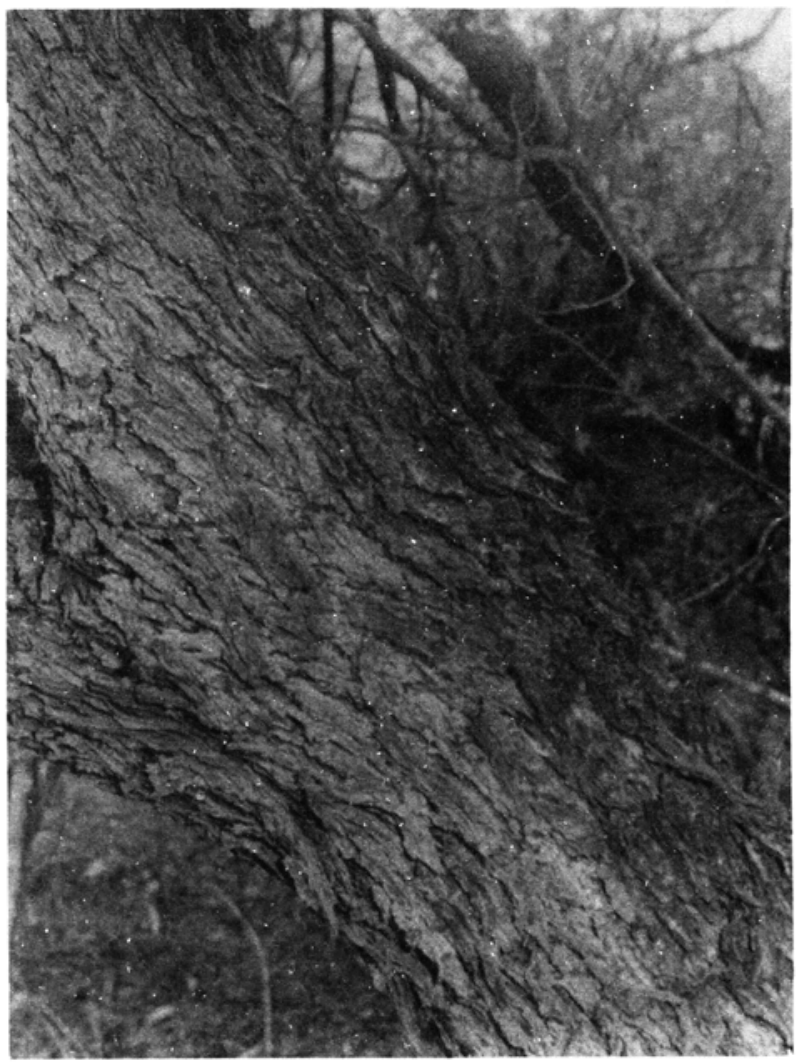

Figura 3 - Aspecto do córtex de Mimosa hostilis Benth., (jurema-preta) ocorrente em Salgueiro-PE. 


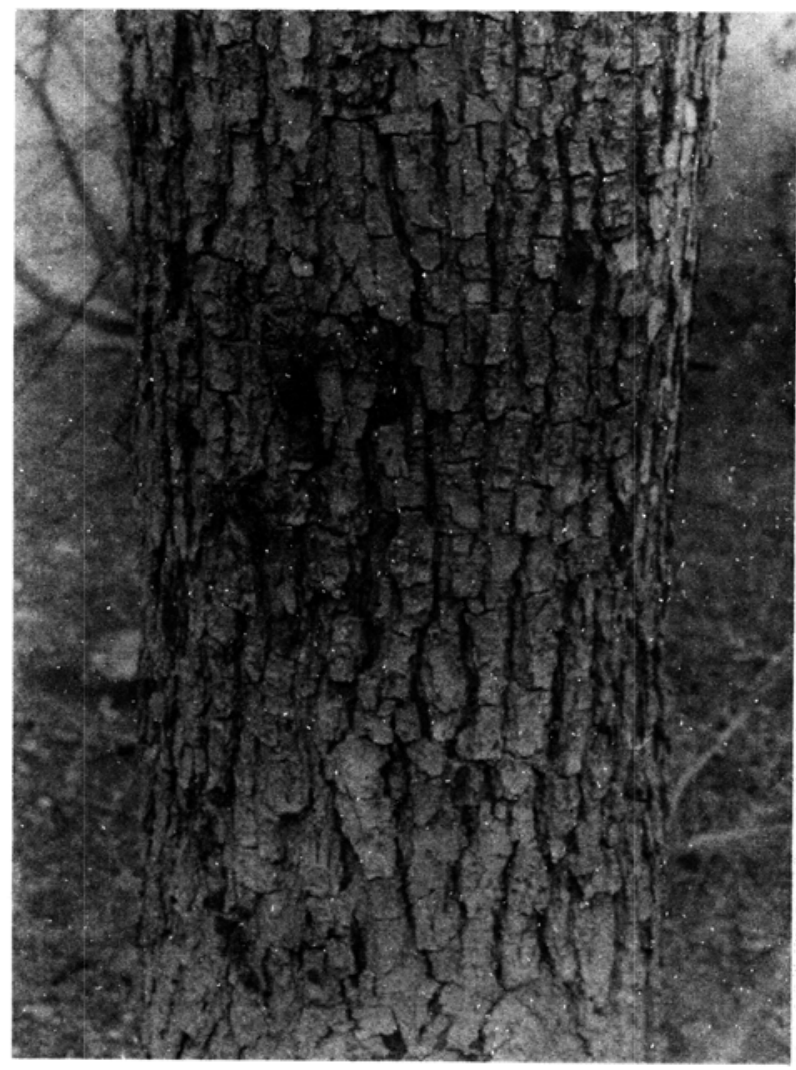

Figura 4 - Aspecto do córtex de Schinopsis brasiliensis Engl. (braúna) ocorrente em Salgueiro-PE. 


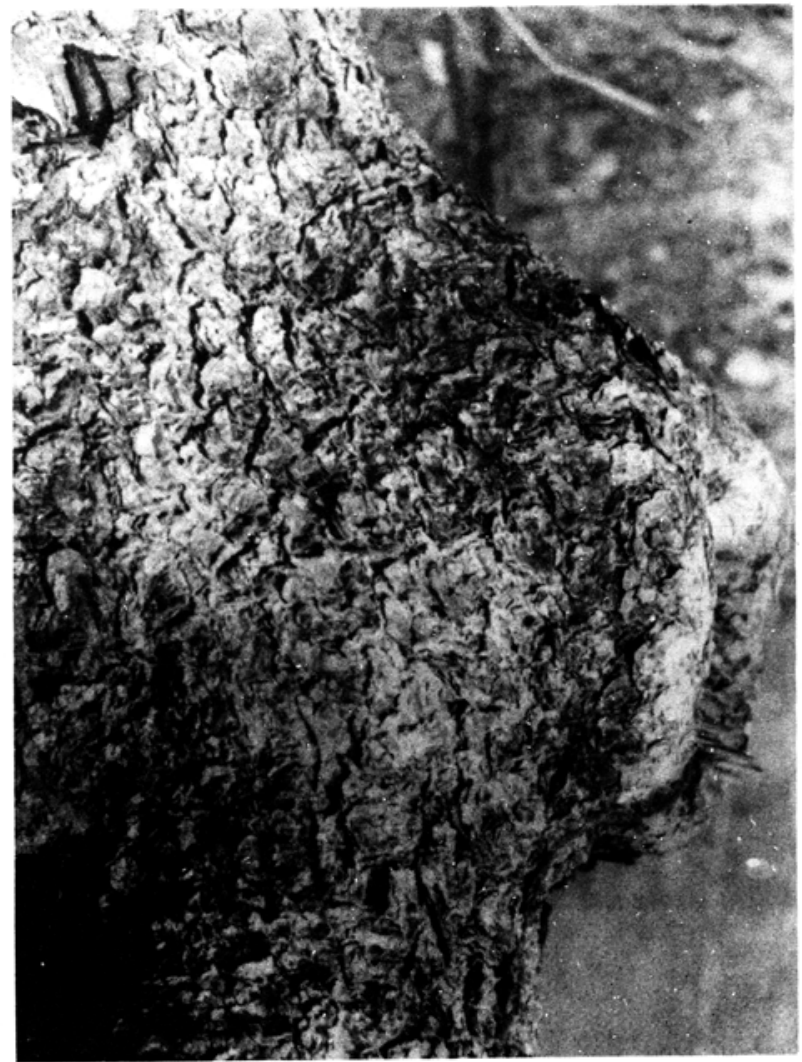

Figura 5 - Aspecto do córtex de Spondias tuberosa Arr. Cam. (umbuzciro) ocorrente em Salgueiro-PE. 


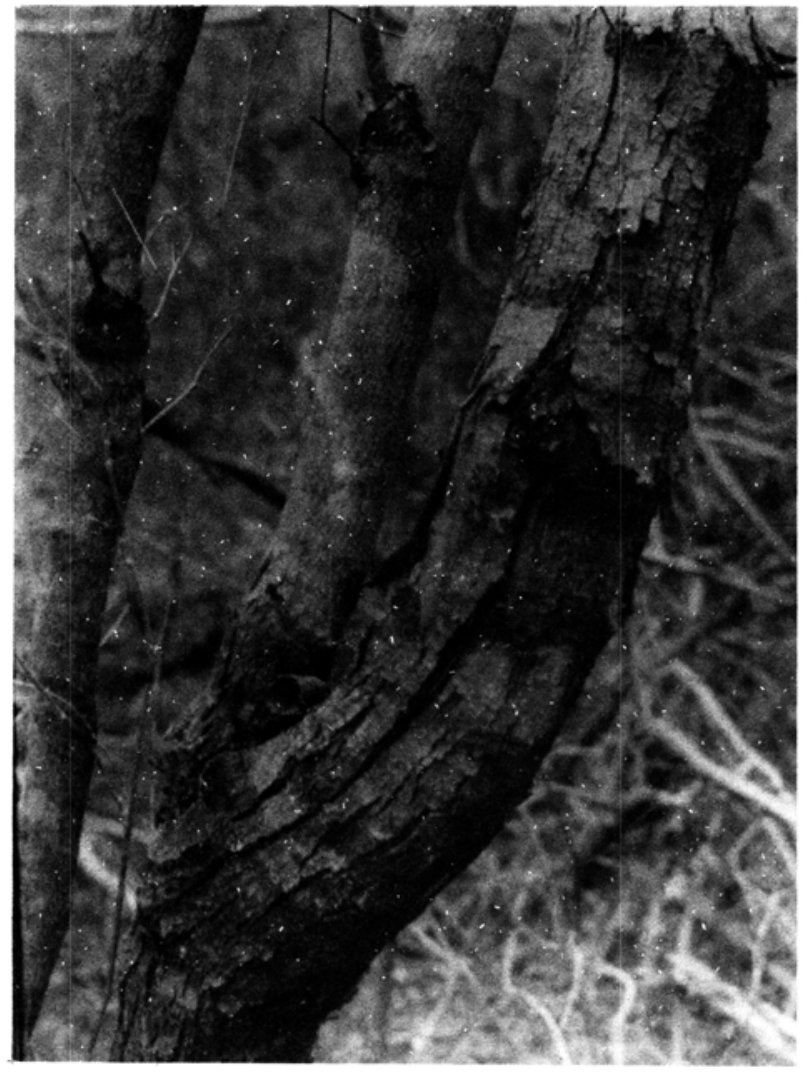

Figura 6 - Aspecto do córtex de Croton sonderianus Muell. Arg. (marmeleiro) ocorrente em Salgueiro-PE. 


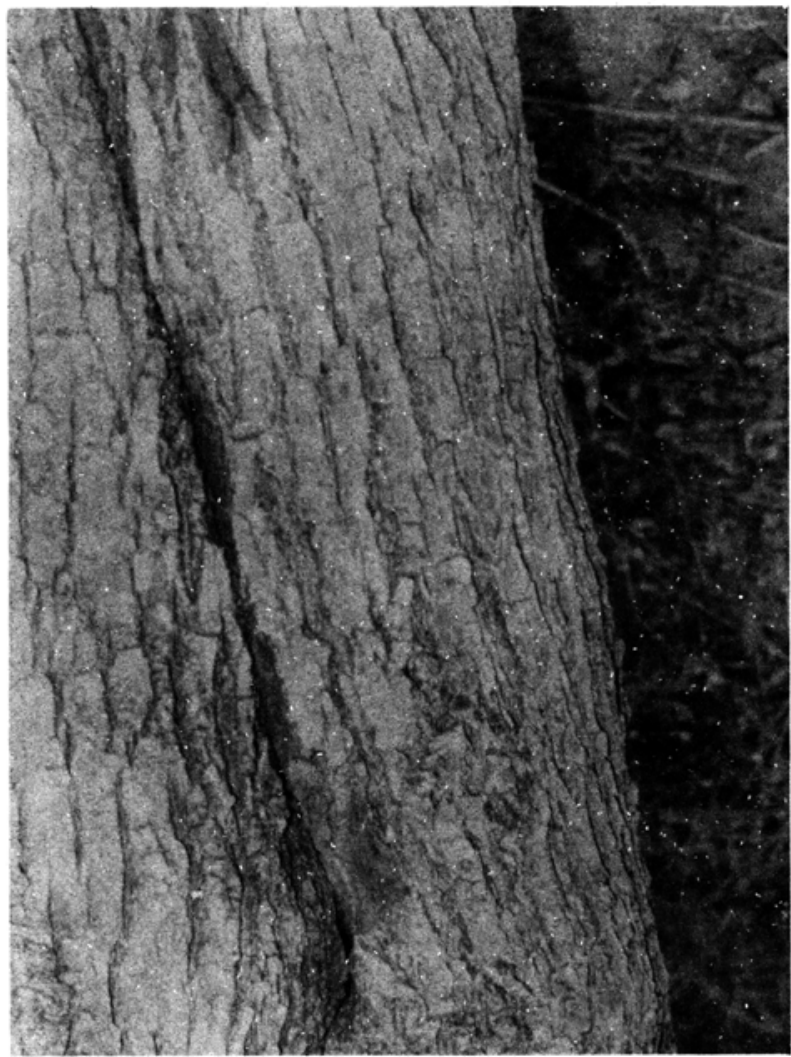

Figura 7 - Aspecto do córtex de Aspidosperma pyrifolium Mart. (pereiro) ocorrente em Salgueiro-PE. 

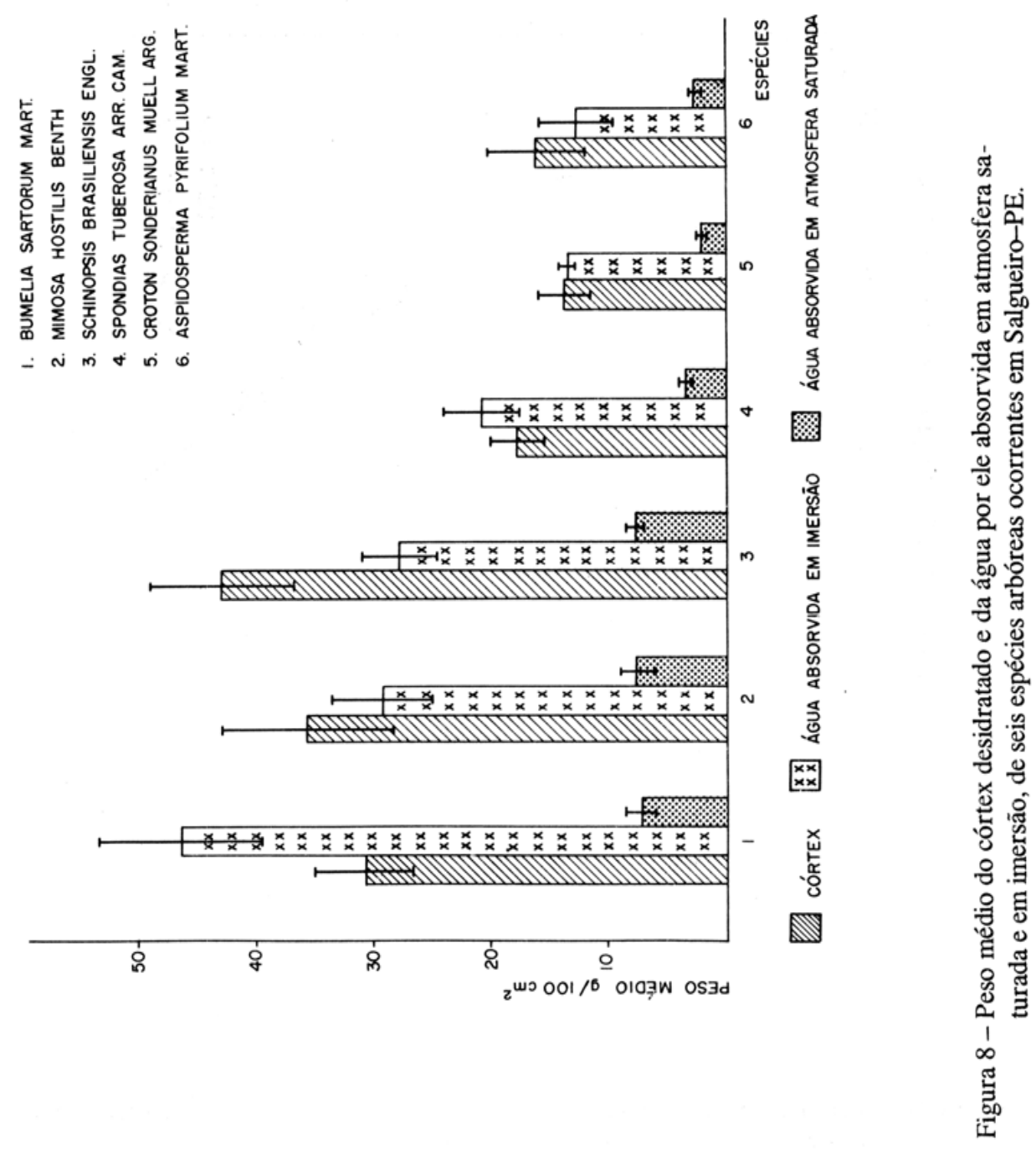
TEOR MÉDIO DE ÁGUA EM $\mathrm{g} / 100 \mathrm{~cm}^{2}$

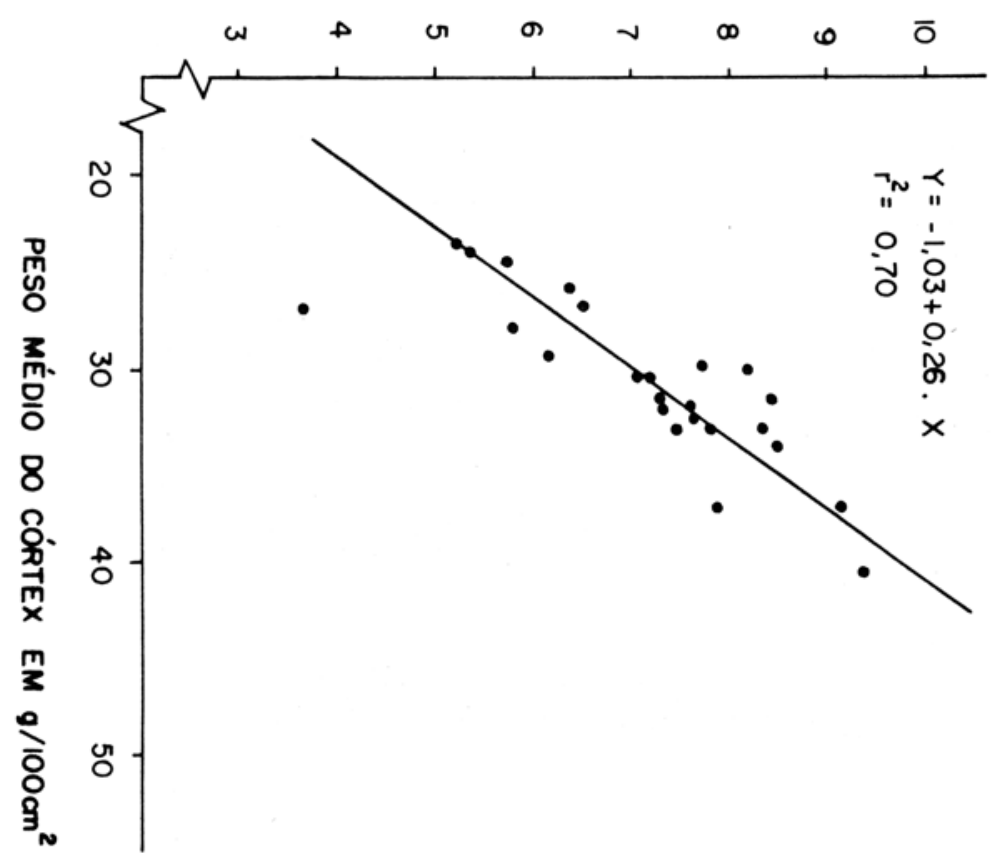

Figura 9 - Correlação entre a água absorvida em atmosfera saturada e o peso seco do córtex de Bumelia sartorum Mart. (quixabeira). 
TEOR MÉDIO DE ÁGUA EM $\mathrm{g} / 100 \mathrm{~cm}$

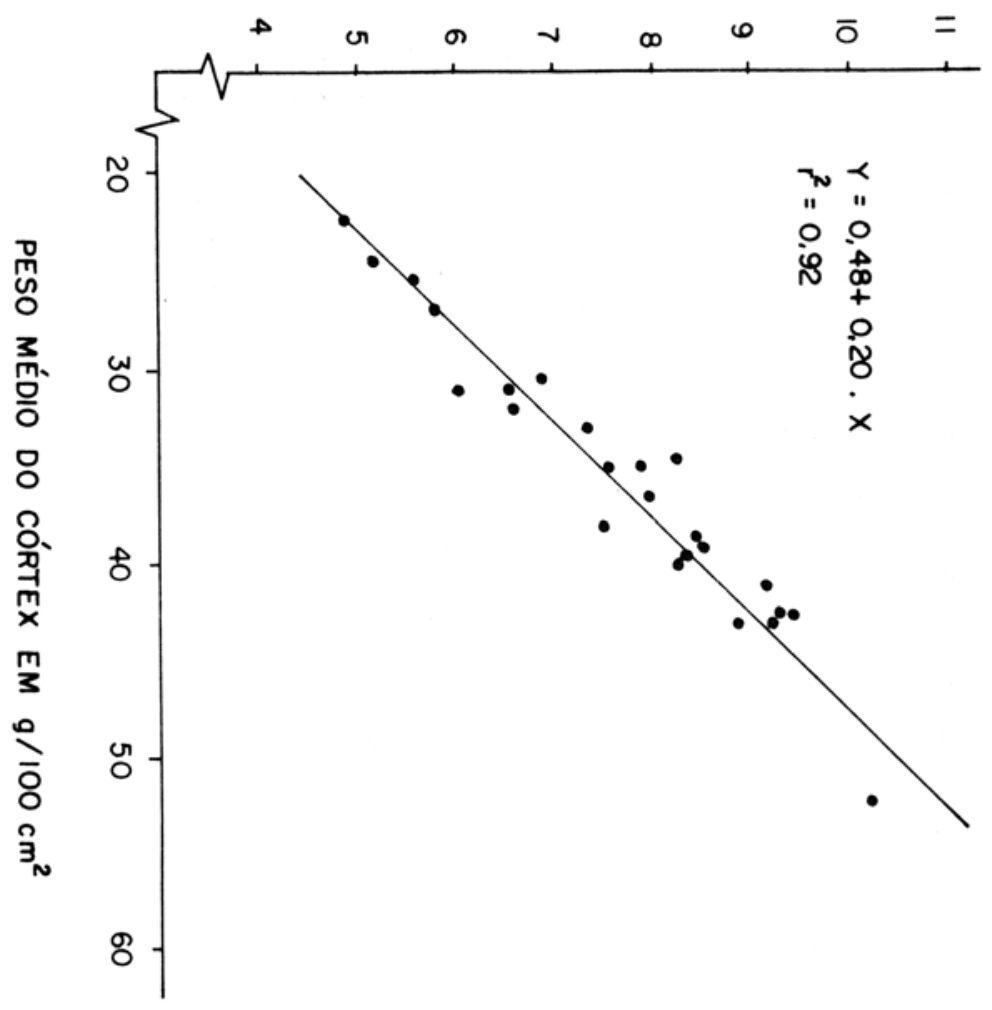

Figura 10 - Correlação entre a água absorvida em atmosfera saturada e o peso seco do córtex de Mimosa hostilis Benth. (jurema-preta). 
TEOR MÉDIO DE ÁGUA EM $\mathrm{g} / 100 \mathrm{~cm}^{2}$

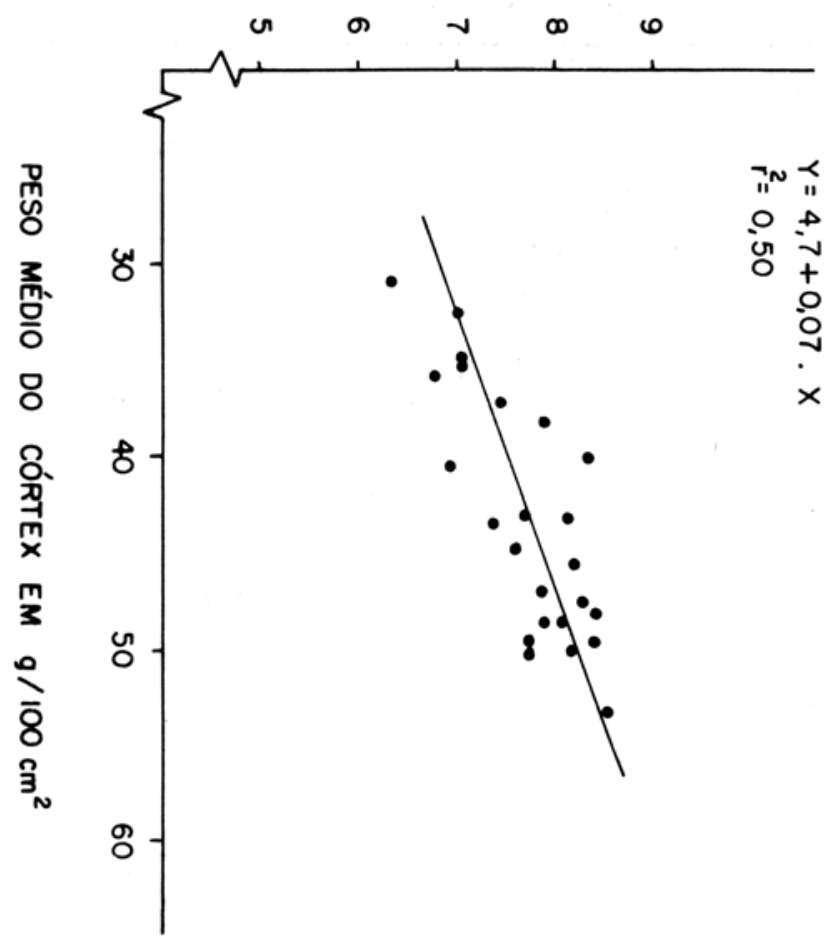

Figura 11 - Correlação entre a água absorvida em atmosfera saturada e o peso seco do córtex de Schinopsis brasiliensis Engl. (braúna). 


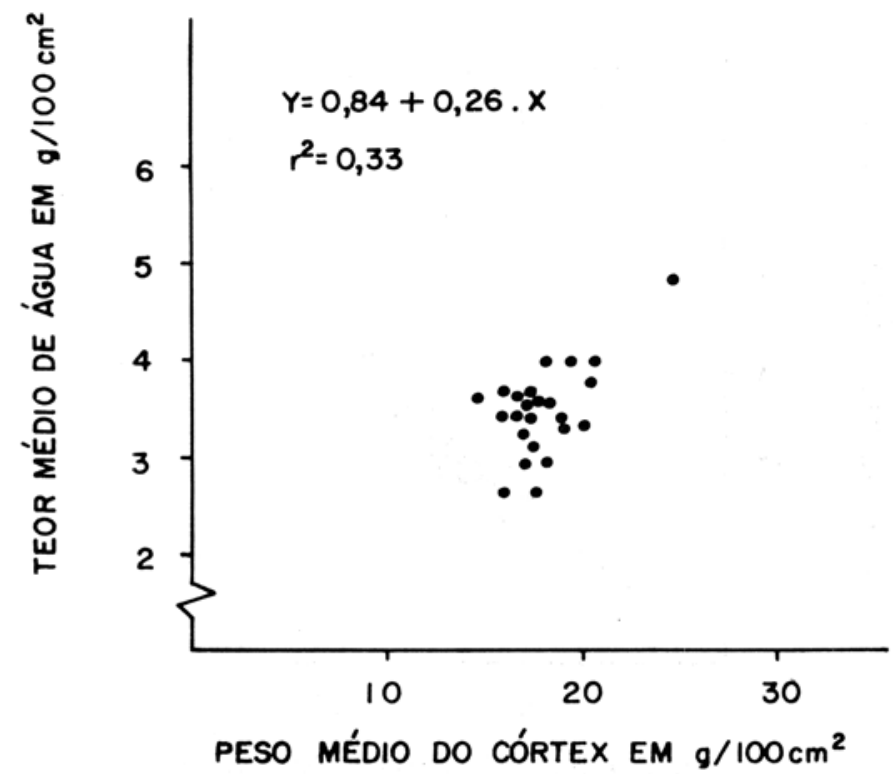

Figura 12 - Correlação entre a água absorvida em atmosfera saturada e o peso seco do córtex de Spondias tuberosa Arr. Cam. (umbuzeiro). 


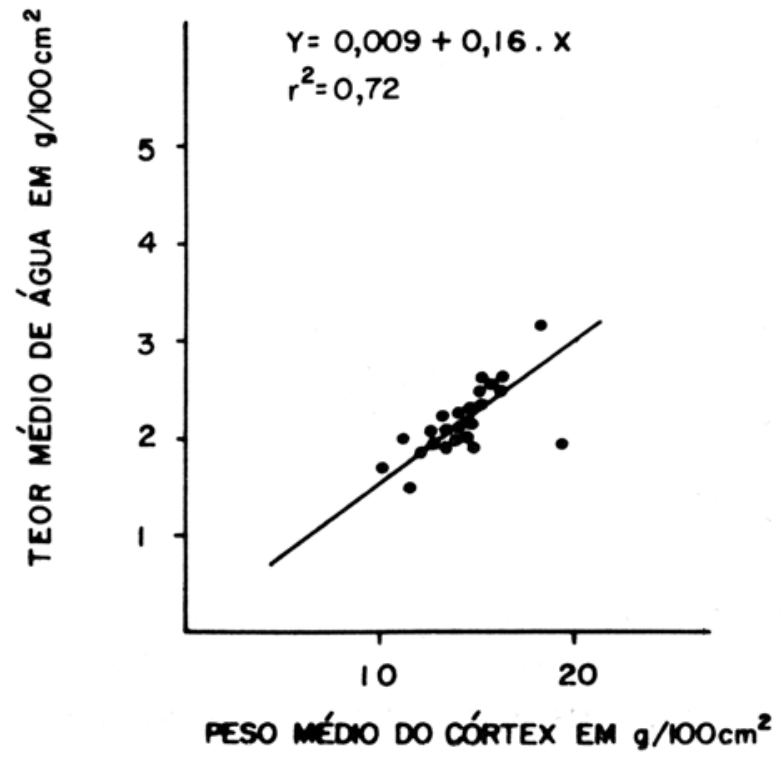

Figura 13 - Correlação entre a água absorvida em atmosfera saturada e o peso seco do córtex de Croton sonderianus Muell. Arg. (marmeleiro). 
TEOR MÉDIO DE AGUA EM $\mathrm{g} / 100 \mathrm{~cm}^{2}$

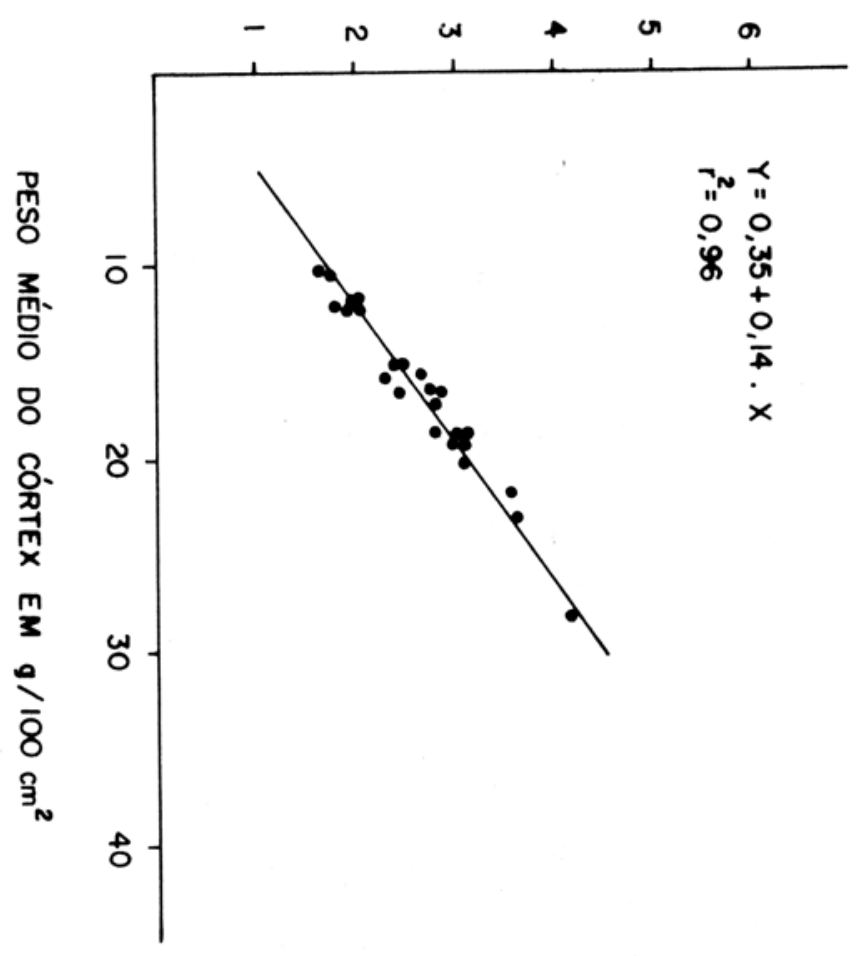

Figura 14 - Correlação entre a água absorvida em atmosfera saturada e o peso seco do córtex de Aspidosperma pyrifolium Mart. (pereiro). 


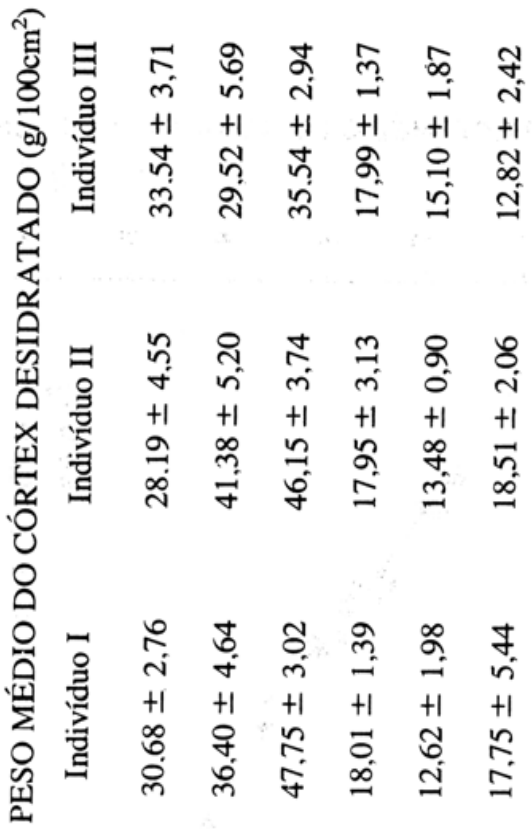

ఫ్త

오 뽐

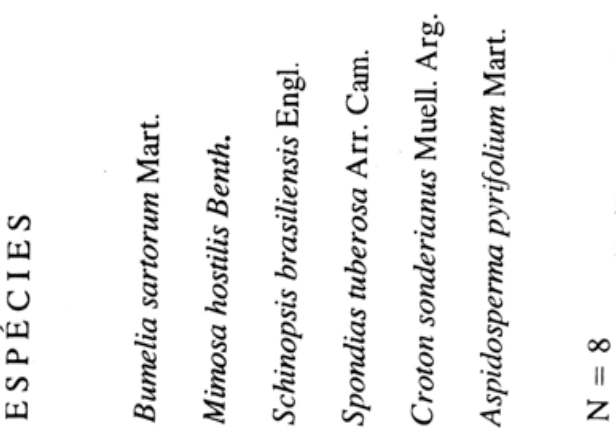

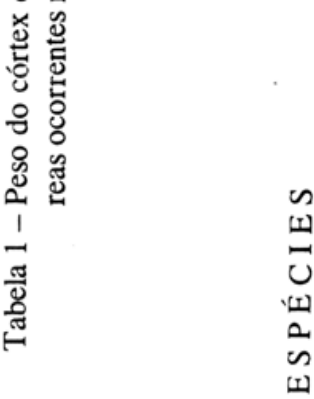


:

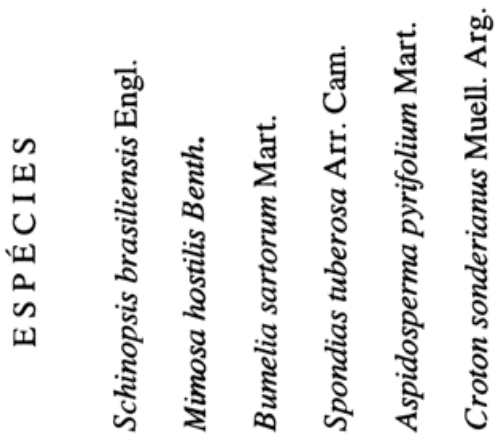

究

땡ㅇㅁ

丞氖

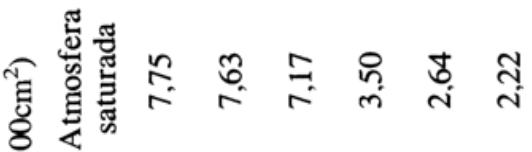

음

มี क

点 ․․․

흠ํㄹ

응

के

. 잉

บิ

음

'త్ల్జ

穿

궁
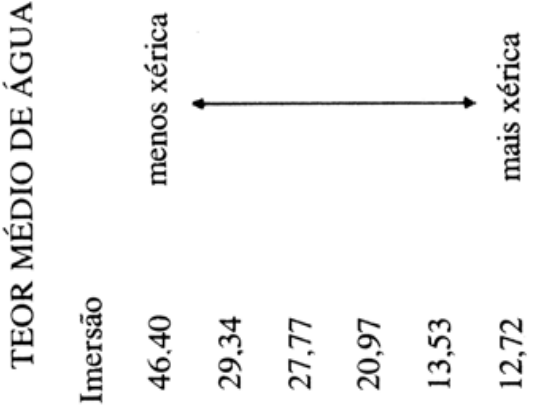

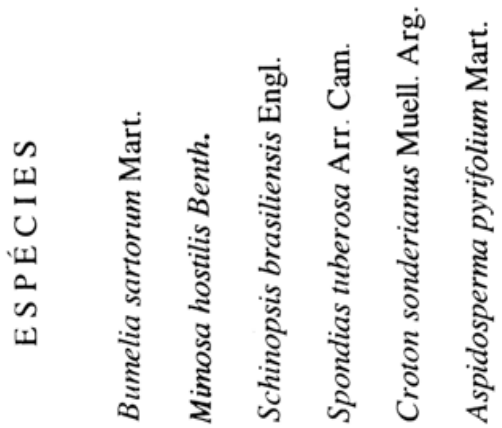

